Unstriated muscle may originate its own action, and within the limits of the influences which necessitate this action it is self-sufficient. The ultimate source of this power, which carries on the vegetative functions, is molecular and colloidal energy released through enzyme action, as marvellous as the energy stored in radium. Cathcart and Benedict estimate that only 25 per cent. of the energy produced in the body can be expended by tissues under the control of the will, 75 per cent. being used by the so-called vegetative functions of the body, of which we are unconscious.

In the intramural plexuses, which to a large extent control motion in the gastro-intestinal tract, we see what might be described picturesquely as pre-sympathetic ganglions, and one might even suggest that this may be true of the sino-auricular node and the bundle of $\mathrm{His}$ in the heart. In the unconscious control of visceral functions through the sympathetic and parasympathetic systems, and the related glands of interaction, one might imagine that the heart is still showing the effect of an early form of control, by primitive emotional centres which existed long before the intellectual organs developed.

\section{Psychic Influences.}

A supreme relationship originated in that shadowy day when hunger and fear, and love and hate, ruled the early ancestral state. Perhaps the psychic influences of this relationship have lost none of their magic. Our emotions and our capacity for aequiring knowledge are hereditary. Emotions may be said to be the outgrowth of those experiences which we call instincts in the lower animals, reactions which existed before the development of true intellectual centres. Unstriated muscle is unconsciously controlled; striated muscle is under conscious control. But the heart is composed of a primitive type of striated muscle. Does this indicate an ancient form of control by unidentified emotional centres? Does the anatomically low origin of the vagus nerve indicate such a primitive cardiac function? Note the direct connexion of the suprarenal glands with sympathetic nerves. In other words, does stern control of the emotions throw stress on the heart, and lead to degeneration of its musculature and to coronary disease?

Do such speculations lead us to believe that by further refinements of diagnosis at the hands of physicians familiar with the electrocardiograph and with other methods of precision the surgeon will be enabled, in early cascs of impending vascular disease of the heart, to relicve the strain on its muscle by division of nerve fibres. or by extirpation of sympathetic ganglionic tracts? In susceptible persons, spasmodic constriction of the arteries in Raynaud's disease, scleroderma of vasospastic origin, and some types of arthritis, eventually leads to vascular obstruction. How about the heart? Is angina pectoris a similar vasospastic phenomenon, and coronary and myocardial disease its ondresult? In the final analysis, heredity may be found to be a controlling factor.

From the Royal Victoria Hospital in Manchester attention has been called to the fact that a common cause of death among surgeons is discase of the heart, especially coronary stenosis, coming on in the latter part of the sixth and the early part of the seventh decade of life. In all cther respects the surgeon maintains his general health equal to others, and often post-mortem examination does not show evidence of other serious disease. The tendency to death from heart disease is not confined to surgeons, but is common to all men who live lives of stress, in which stern control of the emotions is necessary. It is true that much of the disability among surgeons is due to the fact that surgery is to a certain extent a handicraft, and that age and anxiety produce reduction in skill; but, after all, that is not the most serious consideration. The keen clinician, as he grows in experience, becomes more and more valuable as age advances. $\mathrm{He}$ is not exposed to those malign influences of anxiety and responsibility to the same extent as is the surgeon. One might say that the clinician sees his patient drowning and throws him the best means of relief he has, but that the surgeon, in order to give relief, jeopardizes the patient anew.

\section{THE CLINICAL RESULTS FOLLOWING THE OPERATION OF SYMPATHETIC RAMISECTION.*}

BY

N. D. ROYLE, M.D., Ch.M., F.C.S.A.,

ORTIOPAEDIC SURGEON, LEWISHAM HOSPITAL, SYDNEY.

Srmpathetic ramisection was introduced by me in Octoher, 1923, for the treatment of spastic paralysis. It followed upon experiments carried out to investigate the apparent failure of reciprocal innervation in spastic conditions. The results of these experiments are recorded elsewhere. ${ }^{1}$

De Boer had previously found that the normal tonus of the hind limb of the frog and the cat disappeared when the rami communicantes of the sympathetic ganglion were cut. Other investigators obtained similar results, but I was unaware of these when I carried out my experiments.

\section{Discussion of Tone.}

When the limb was deprived of its sympathetic nerve supply it behaved differently to a normal limb in that jt showed a loss of resistance to passive movements; in addition, it exhibited an inability to oppose gravity in the decerebrate, anaesthetized, and normal passive animalthat is, there was a loss of the posture-maintaining mechanism. The different behaviour of a limb deprived of its sympathetic nerve supply was attributed to a loss of tone.

There is considerable controversy about the exact nature of tone, and a definition is difficult to give, but the definition that $I$ use is that tone is the expression of a proprioceptive mechanism subserving posture, and is present in muscles which have been stretched or are being stretched--that is to say, it is not exhibited to any extent by muscles at rest.

Over this mechanism of tone we have no conscious control except as a concomitant to active contraction. There is a small amount of tone in a normal muscle which is overcome by the contraction of the opposing group, but is not directly inhibited. Though I do not subscribe to the idea of co-contraction, tone is certainly induced by stretching the opposing group in any movement.

The upper eyelid maintains a definite posture in the waking stage in response to the stretching imposed by gravity. We cannot voluntarily make this posture any more fixed or any less fixed, but the tone is not sufficient to impede movement in changing the position of the lids. If through some pathological change tone becomes abnormally increased, as it does in spastic paralysis, it not only increases the tendency to maintain posture, as is showi by the persistent attitudes of spastic hemiplegia, or by the inability to balance in spastic paraplegia on account of rigid limbs, but it also forms an obstruction to movement. There is an apparent failure of reciprocal innervation due to an increase in tone in opposing groups of muscles. For example, the excessive tone of the flexors of the elbow or knee induced by stretching cannot be inhibited when the extensors are contracting. Although this may not appear in the laboratory animal, it does in the intact human subject.

The chief indication for the operation of sympathetic ramisection is the failure of inhibition in voluntary muscles. This is expressed by delayed relaxation time in reflexes, as in the knee-jerk, and by the inability to relax the muscles quickly. There must also be present definite cortical control over the muscle group for the operation to be effective. The essential change following a ramisection is that the patient no longer has to inhibit the excessive tone of his formerly contracted hypertonic muscles if cortical control is present. Sympathetic ramisection does not remove contractures of fibrous tissue, nor does it restore cerebro-spinal pathways. It decreases tone, and thus enables patients to move smoothly and more rapidly. Movements are gained or regained as a result of operative treatment, as in the intrinsic muscles of the hand or the common extensors of the fingers, because the patient is

* Read in opening a discussion in the Section of Surgery at the 
able to relax the opposing groups. The relaxation of flexion of the fingers, for example, allows extension to be performed. (This statement does not apply in athetosis.)

Results in Various Spastic Conditions.

I have now performed the operation of sympathetic ramisection approximately six hundred times with three deaths. Two of these deaths were from embolus shortly after the operation, and one was from pneumonia in the first week following operation. Thus the operative death rate is 0.5 per cent. Approximately three hundred patients underwent operation, and two operations were performed upon each patient. In some instances all four limbs were deprived of their sympathetic nerve supply. In the case of the upper limb, it is interesting to note, a sympathetic trunk section performed bilaterally in the upper thoracic region has not apparently a detrimental effect on the cardiac mechanism. Many patients were able to play vigorous games after operation without discomfort. Many of the operations I performed must be regarded as experimental.

To ascertain the effect of operative treatment in spastic paralysis and allied conditions, I sent a questionary to each of my patients and received one hundred and twentysix replies, and in each case it is from the patient's or parent's own opinion of the improvement that the figures are compiled. My records show that the remainder of the patients that did not reply had similar if not better results. The patient or parent is, after all, the best judge of improvement, although he is not able to recognize the phrsiological changes following ramisection when complicated by some other condition. For example, one parent returned the answer, "No result at all," when to my knowledge and from cinematographic records the practical and physiological result was good, but was marred by the presence of bilateral talipes calcaneus, which did not allow the patient to walk properly. Another patient, 23 vears of age, who walked for the first time in her life six weeks after operation, returned the result, "Good, with room for improvement." I think most surgeons who treat spastic paralysis would have classified the result as excellent.

The following are the patients' own opinions of their improvement in answer to the question if the results could be classified as: (1) excellent, (2) good, (3) poor, (4) no result at all.

Congenital Spastic Paraplegia.

Thirty-seven patients or parents replied as follows:
Excellent...
Good
8 (21.62 per cent.)
Poor
$\ldots 20(54.05$ per cent.)
No result at all $\quad \ldots \quad \ldots \quad \ldots \quad \ldots \quad 4$ (10.8 per cent.)

Some result was obtained in at least 88 per cent. of all patients and good or excellent results were obtained in 75.6 per cent.

C'ongenital Spastic Hemiplegia.

Thirty-five patients or parents replied as follows:

$\begin{array}{llllll}\text { Excellent } \ldots & \ldots & \ldots & \ldots & \ldots & 11 \text { (31.42 per cent.) } \\ \text { Good } \quad \ldots & \ldots & \ldots & \ldots & \ldots & 14 \text { (40 per crpt.) } \\ \text { Poor } \ldots & \ldots & \ldots & \ldots & \ldots & 9 \text { (25.71 per cent.) } \\ \text { No result at all } & \ldots & \ldots & \ldots & 1 \text { (2.85 per cent.) }\end{array}$

Some result was obtained in 97 per cent. and an excellent or good result was obtained in 71.4 per cent. Many of these results followed my old operation of cervical ramisection. On October 6th, 1929, I introduced a more complete operation, and the recent results are better.

Congenital Spastic Chorea.

Ten paticnts or parents replied as follows:

$\begin{array}{lcccccc}\text { Excellent } & \ldots & \ldots & \ldots & \ldots & \ldots & 3 \text { (30 per cent.) } \\ \text { Good } \ldots & \ldots & \ldots & \ldots & \ldots & \ldots & 4(40 \text { per cent.) } \\ \text { Poor } \ldots & \ldots & \ldots & \ldots & \ldots & \ldots & 3 \text { (30 per cent.) } \\ \text { No result at all } & \ldots & \ldots & \ldots & \ldots & \text { nil }\end{array}$

In patients suffering from this disease some result was obtained in 100 per cent. and an excellent or good result was obtained in 70 per cent. Patients with all degrees of spastic chorea wore treated, from those with spasm which resembled decerebrate rigidity to those with chorei-

form movements preventing the patient feeding himself or standing up properly. This so-called spastic chorea is not a true spastic condition, as the patient is really not spastic during his quiescent periods. That is to say, there is no opposition in passive movement, but the patient is unable to inhibit the choreiform movements.

\section{Acquired Spastic Hemiplegia.}

This section includes cases arising from cerebral haemorrhage, embolus, gunshot wounds, and trauma. In most patients my old operation of cervical ramisection was performed.
Excellen
4 (21.5 per cent.)
Good
7 (36.8 per cent.)
No result at all ...
… 7 ( 1 ( 36.8 per cent. $)$

Some result was obtained in 94 per cent. and an excellent or good result in 58 per cent. The results are very much better with thoracic sympathetic trunk section, as shown by the result of a more complete operation in the following case report.

Thirty-eight years previously the patient had had what was described as a heat stroke, resulting in a fit. This was followed by loss of function in the right upper limb. She had had various forms of treatment, and when she presented herself she had regained the ability to move the hand, but the movements were slow and difficult. She could not extend her fingers with the wrist dorsiflexed, nor could she supinate the hand or extend her arm above her head. She had some control of the intrinsic muscles, but she could not place her thumb on the little finger. The reflexes were hyperexcitable and the relaxation time was prolonged. There was resistance to passive movements of the right upper limb in all directions.

. Right - sympathetic thoracic trunk section was performed on April 2nd, 1930. This was followed by an immediate loss of tone and relief of her spastic condition. She regained the movement of dorsifexion of the wrist and supination of the forearm within a few days. The patient was able to shake hands; this was the first time she had used her hand in this way for thirty-eight years. She could put her thumb on her little finger with ease and the control of her intrinsic muscles was very much improved.

\section{Acquired Spastic Paraplegia.}

The patients in this group include those suffering from disseminated or lateral sclerosis.

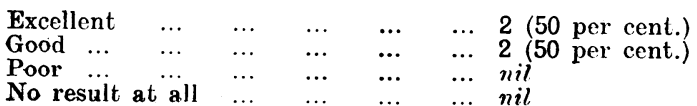

Exrellent or good results were obtained in 100 per cent. but the numbers are too small to be reliable. From my records I know that other patients did not obtain satisfactory results, but I performed many experimental operations in practically hopeless conditions. In lateral sclerosis there is no hope of obtaining results if the cerebro-spinal pathways are sclerosed and incapable of transmitting motor impulses.

Parkinsonian Rigidity.

Twenty-two patients replied as follows

$\begin{array}{lccccccc}\text { Excellent } & \ldots & \ldots & \ldots & \ldots & \ldots & 1 & (4.5 \text { per cent.) } \\ \text { Good } & \ldots & \ldots & \ldots & \ldots & \ldots & 5 & 22.7 \text { per cent.) } \\ \text { Poor } & \ldots & \ldots & \ldots & \ldots & \ldots & 9 & (40.76 \text { per cent.) } \\ \text { No result at all... } & \ldots & \ldots & \ldots & 7 & (31.7 \text { per cent.) }\end{array}$

Some result was obtained in 68 per cent. of these patients and an excellent or good result in 27 per cent. The large returns for " poor" or " no result at all " are due to the effects of the progressive sclerosis which is associated with this disease. There are changes in reflex activity and in movement after ramisection, and these remain, but the patient gradually loses initiative, and it is this mental change which modifies the practical result. The tremor of paralysis agitans is modified only, but not removed, by ramisection.

Chronic Constipation and Megalocolon in Adults.

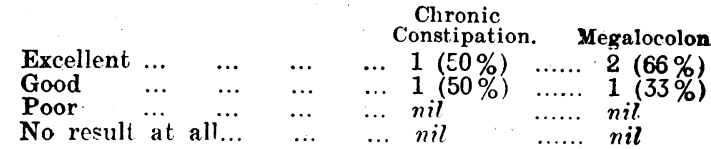


An excellent or good result was obtained in 100 per cent. in each class of disease.

The operative treatment of chronic constipation and Hirschsprung's disease followed my observations made in patients suffering from spastic paralysis. These spastic patients are commonly constipated, and the results following ramisection were so striking that $\mathrm{Dr}$. R. B. Wade applied a modified ramisection to the condition known as Hirschsprung's disease in children. ${ }^{2}$ I have operated on five adult patients-three with dilated large bowel and two with chronic constipation. The following two histories indicate the condition before and after operation.

CASE I.

This patient, a female, aged 28 , had always been constipated. Four "alophen" pills would produce only a slight movement of the bowel. She stated that it was usual for her to have an interval of eight days between motions. She had always suffered with indigestion. She complained of ill-health and inability to perform her household duties.

On examination her knee-jerks were found to be hyperexcitable, with slow relaxation, and there were no oscillations. This was more apparent on the right side than on the left, and was taken as evidence of sympathetic hyperactivity.

A modified left lumbar sympathetic ramisection was performed on October 24th, 1929. On December 3rd she had very much improved; she had lost the pain in her back and the movements of her bowel were normal. When seen on May 7th, 1930, she stated that she had gained a stone in weight, that she had not taken any aperients for over six months, and that she was feeling particularly well.

CASE II.

The patient, aged 58, complained of fatigue, slight nausea, and sleeplessness. He stated that at times he had previously been constipated for ten to fourteen days. On the last occasion four weeks had elapsed since be had had a normal motion. These attacks had occurred about every four months for the last twenty years. He had had tonsillitis as a child and malaria when 40 years of age. Appendicectomy had been performed at the age of 47, and his tonsils and devitalized teeth had been removed one year later. His basal metabolic rate was +22 . The patient stated that he felt mentally fatigued and hazy during attacks. No abnormality was discovered in the urine. Radiological examination. showed a dilated pelvic colon. The reflexes were hyperexcitable and retarded in relaxation. Ho had a very bad colour and perspired freely.

A modified sympathetic ramisection was performed on May 6th, 1930. He was given an aperient which caused a motion on the second day. Since then he has had a motion every day. An interesting point is that the reflexes returned to normal after operation, and the patient has lost what he described as haziness in his mental outlook.

\section{Sarcoma of the Femur.}

The effect of ramisection on the lymphatic circulation is illustrated in a patient suffering from a sarcoma of the lower end of the femur.

In this patient amputation of the limb was considered useless owing to the $x$-ray appearances of the tumour and the duration of its growth. The patient suffered extreme pain. This was completely relieved by sympathetic ramisection, and there was in addition, a shrinkage of the tumour. Shrinkage was so rapid that it could be due only to improvement in the lymphatic circulation. Before operation the growth measured $38 \mathrm{~cm}$. in circumference, and on the afternoon following operation $36.5 \mathrm{~cm}$. Eleven days after operation it measured $34.8 \mathrm{~cm}$. Secondary growths in the inguinal region then appeared and involved the blood vessels, particularly the veins and lymphatics, and the growth gradually increased in size, though it did not attain the size it was before operation. The patient died about three months after operation. Professor. Welsh of the University of Sydney reported the growth to be a fibro-sarcoma.

Raynaud's Disease and Buerger's Discase. Thirteen patients replied as follows:

\begin{tabular}{|c|c|c|c|c|c|}
\hline & & & & $\begin{array}{l}\text { Raynaud's } \\
\text { Disease. }\end{array}$ & \\
\hline $\begin{array}{l}\text { Excellent } \\
\text { Good } \\
\text { Poor }\end{array}$ & $\begin{array}{l}\ldots \\
\ldots \\
\ldots\end{array}$ & $\begin{array}{c}\cdots \\
\cdots \\
\cdots\end{array}$ & & $\begin{array}{ll}\ldots & 5(71 \%) \\
\ldots . & 2(28 \%) \\
\ldots . & n i l\end{array}$ & $\begin{array}{l}\ldots \ldots . . \\
\cdots \cdots . . \\
\cdots \cdots . .\end{array}$ \\
\hline
\end{tabular}

An excellent or good result was obtained in 100 per cent. in Raynaud's disease and in 66 per cent: in Buerger's disease.
A constant and most obvious change that follows ramisection is vaso-dilatation. This was described by me in my first paper, and the observation was used by Adson and Brown in their application of a modification of ramisection in Raynaud's disease. The sympathetic supply to a lower limb may be entirely removed by dividing the laterally directed rami to the second, third, and fourtl lumbar nerves, and by dividing the lumbar sympathetic trunk at the level of the fourth lumbar vertebra. What is the reason, therefore, for removing part of the nerve supply of the bladder and bowel at the same time? The necessity for opening the peritoneum is also not obvious, but it is done by some surgeons as a routine procedure. It is a more dangerous and shock-producing operation, and is accompanied by a higher death rate than operations by the lumbar route.

I have operated in seven instances for Raynaud's disease with successful results, and in six instances upon patients with thrombo-angiitis obliterans with successful results in four.

\section{Writer's Cramp.}

Writer's cramp is a condition which can be treated by surgery of the sympathetic nervous system, as illustrated by the following case history.

The patient complained of inability to write. This was due to retraction of the hand controlling the pen. When he attempted to write, the thumb and wrist flexed, and this movement was accompanied by severe pain. The onset had been sudden, and had occurred seventeen years previously.

A thoracic sympathetic trunk section was carried out in August, 1928 , and the pain and spasm immediately disappeared. At the end of six months he was able to.write from two to four hours a day. The character of his writing also improved. In June, 1930, he wrote: "I can write more freely and for long periods. The pain and spasm have completely left me."

From this result it may be expected that the condition known as "telegraphist's cramp" may be successfully treated by operation on the sympathetic nervous system.

\section{Anterior Poliomyelitis.}

The application of sympathetic ramisection to the paralysis left by anterior poliomyelitis leads to satisfactory results as far as the paralysis is concerned. There was definite increase in power in one or two instances. In one instance, in answer to the questionary, the parent of the patient classified the result as "good," stating that there was little difference in the size of the two lower limbs compared with what there had been, that her circulation had improved, and that she was walking much better. There are, in my opinion, very few instances, however, in which the operation of sympathetic ramisection could be applied to anterior poliomyelitis, but there are perhaps a few in which general weakness of a limb could be improved by increasing the blood supply.

Conditions Simulating Tic Douloureux.

A patient, aged 9 years, complained of pain in the right side of the face for a period of two years. The pain was not constant, but occurred in severe exacerbations two or three times a veek, and was referred to the distribution of the trigeminal nerve. During attacks the face became flushed, and the flushing was accompanied by excessive lacrymal secretion and secretion from the right side of the nose. Eating of ten precipitated a spasm, but at other times it came on from no obvious cause. He also complained of pain in the lower end of the spine when the pain in the face was present. The pain was agonizing and made the patient cry. After the pain had passed off the patient felt cold, and passed quantities of light-coloured urine.

On examination the face was a little more sensitive on the right side. $X$-ray examination of skull, pelvis, and jaw showed no evidence of any pathological change, and the patient's serum did not react to the. Wassermann test.

Thoracic sympathetic trunk section was performed on February 13th, 1930, and this was followed by attacks which gradually increased in severity and number. He had nine attacks in two weeks. The attacks then ceased, and he has had none since. The patient has now been free from pain for over six months.

The diagnosis of this condition may be disputed on account of the age of the patient, but the pain was referred to the trigeminal supply. The attacks did not cease immediately; this may be explained on the basis of paralysis of circulation and increased congestion following division of sympathetic nerves to one side of the head. 
Unusual Vaso-spastic Conditions.

The following two case reports relate facts that are not usually described in medical literature.

\section{Case I.}

The patient was a girl of 14 years of age, who had sudden pain in her right foot two and a half vears ago. This was accompanied by swelling of the foot and leg. The first attack lasted for three weeks and disappeared as suddenly as it camo on. Occasionally she had been two months at a time without symptoms, but she had a prolonged attack in 1929-from February to May. For the last six months pain and swelling had been present every two or three days. The attack prior to operation had lasted seven weeks.

On examination pulsation was felt in the posterior tibial and anterior tibial arteries at the ankle. The deep reflexes were hyperexcitable and prolonged in relaxation on the right side, normal on the left. The right lower limb was cold, and there was excessive vasomotor tone, as evidenced by the slow return of colour after the removal of pressure.

Sympathetic ramisection of the right lower limb was performed on May 10th, 1930. This was followed by an immediate cessation of pain and disappearance of swelling. There has been no recurrence of her symptoms since the operation.

Case II.

- For about two years this palient had suffered from coldness in the left lower limb. The right lower limb was also affected, but not. so badly. This prevented the patient from sleeping a night, and was accompanied by a feeling of heaviness and profuse perspiration. The condition had been treated elsewhere as neuritis. Exercise made the leg warmer, but it became cold soon after the patient rested.

Left lumbar sympathetic ramisection was performed on October 2nd, 1929. This was followed by immediate relief and cessation of perspiration and coldness. The right lower limb also improved as a result of operative treatment of the left side. Improvement has been maintained up to the present time.

\section{Retinitis Pigmentosa.}

The latest, and a most important, application in surgery of the sympathetic nervous system is in the treatment of blindness associated with retinitis pigmentosa. This disease is characterized by degeneration of the retinal tissues and an accumulation of pigment in the substance of the retina consequent upon degeneration and constriction of the retinal vessels. The idea that the disease is caused by degeneration of retinal vessels is supported by experimental evidence. Another suggested cause is that the disease is due to a primary degeneration of nerve tissue, but it is doubtful that this occurs apart from some alteration in blood supply.

The subjective signs of the disease are: (1) night-blindness; (2) loss of visual acuity; (3) contraction of fields of vision; (4) in advanced cases total blindness.

My attention was first directed to the pathological changes in the blood vessels in this disease by $\mathrm{Dr}$. Lawrence, ophthalmic surgeon of Melbourne, and I thought that, as division of the sympathetic supply of the eve would permanently dilate the vessels, the conditions underlying the disease might be altered with beneficial effect. Di. E. A. Brearley, ophthalmic surgeon of Srdney, sent me the patients and examined them after treatiment.

The operation I carried out upon these patients was thoracic sympathetic trunk section, and consisted in dividing the sympathetic trunk just about the level of the second thoracic ganglion. This operation has been described elsewhere. ${ }^{3}$

\section{Results of Operation.}

The first patient underwent operation on May 29th, 1930 During the week after operation he did not improve, but since then there has been steady improvement in the acuity of vision and in the enlargement of the fields of vision. The patient had had retinitis pigmentosa for the past ten years. Prior to operation he could not see clearly; evervthing was misty; for example, he could not see fingers moving at a distance of four feet. He was totally blind in the dark. He had sufferer from blepharospasm of the right eye for three months prior to operation. Two weeks after operation he could tell the timo on a clock with a two-inch dial, black figures on a white ground. He could also distinguish fingers moving at a distance of four feet. On June 18th he was very much improved; he could read letters half an inch high and the face of an alarm clock with a four-inch dial at a distance of eight feet. On June 24th he reported that the fields of vision were enlarged and that the vision of the left eye was also improved, although the right thoracic sympathetic trunk only was divided in the operation. He also reported that he could read small print in a good light. The blepharospasm disappeared.

The other four patients have also had some improvement in the acuity of vision and enlargement of the fields of vision, but it is too early to state the results accurately excepting in one instance, in which the field of vision was eniarged three times in a month.

\section{Royle, N. D.: A New RereneNces \\ Spastic Paralysis and It Experimental Basis, MIed. Journ. of Australia, January 26th, 1927, p. 77. Wade, R. 'B., and Royle, N. D.: The Operative Treatment of
Hirschsprung's Disease: A New Method, ibid., January 29th, 1927, p. 135 . \\ : Sympathetic Trunk Section: A New Op ration for October 6th, 1928, p. $4 \imath^{2} 6$.}

\section{GENERAL OUTLINE OF THE PROBLEM OF TRAINING HEALTH WORKERS.*}

J. G. FITZGERALD, M.D., LL.D.,

PROFESSOR OF HYGIENE AND PREVENTIVE MEDICINE, DIRECTOR OF THE SCHOOL OF HYGIENE AND OF THE CONNAUGHT LABORATORIES, UNIVERSITY OF TORONTO.

THE topic assigned to me in this symposium is the "General outline of the problem of training health workers." Health workers include university graduates in medicine, arts or science, engineering, agriculture, public health nursing, social science, and those who have received training in the duties of a sanitary inspector. Many of these possess a basic professional training and have also spent one or more years qualifying as public health administrators, bacteriologists, engineers, statisticians, etc.

In connexion with the vocational preparation of health workers, it is pertinent at the outset to consider whether universities can reasonably be expected to provide course of study for those who wish to equip themselves for any and every type of public health work. In some universities it may be quite impossible under existing financial conditions to assume any responsibility for graduate work in public health. Others may content themselves with undergraduate teaching of the subject in the medical, arts, science, and engineering faculties. Still other institutions may indicate that they provide graduate instruction for those equipped and trained by suitable undergraduate study to profit by instruction of a real university graduate character. The fact is that university schools of hygiene in North America are largely, at the present time, limiting their activities to the preparation of students who are graduates in medicine, arts, science, or engineering. Exceptions are found in Canada, where a university school of hygiene has assumed a share in the responsibility for the instruction of graduate nurses (not university graduates) who are registered in oneor two-year certificate or diploma courses.

Adequate arrangements for the conduct of graduate work in public health or preventive medicine in a university school of hygiene leading to the degree of master of arts or doctor of science or of philosophy usually presents a monetary problem only. Assuming adequate appropriations and a suitably qualified staff, real graduate work in epidemiology, physiological hygiene, infection, and immunity, as well as in other cognate subjects, can be carried on. It is hardly necessary for such graduate students to have access to health departments, even though such a contact may have mutual advantages. Those engaged in qualifying as specialists in public health are, as a rule, doing research and possibly some teaching and will probably be called upon to occupy university positions or direct the work of certain divisions in large and important health departments. This portion of the student body of a university school of hygiene constitutes a very essential part of the whole public health occupational group. To neglect recruiting for this unit may lead to serious difficulties in the future. Public health, like

* Read in opening a discussion in the Section of Preventive Medicine 